\title{
Ontogenic Resistance to Powdery Mildew in Grape Berries
}

\author{
David M. Gadoury, Robert C. Seem, Andrea Ficke, and Wayne F. Wilcox
}

Department of Plant Pathology, Cornell University, New York State Agricultural Experiment Station, Geneva 14456. Accepted for publication 10 December 2002.

\begin{abstract}
Gadoury, D. M., Seem, R. C., Ficke, A., and Wilcox, W. F. 2003. Ontogenic resistance to powdery mildew in grape berries. Phytopathology 93:547-555.

Berries of Vitis vinifera are reported to be susceptible to infection by Uncinula necator until soluble solids levels (brix) reach 8\%, and established colonies are reported to sporulate until brix reach $15 \%$. However, our analysis of disease progress on fruit of selected $V$. vinifera cultivars indicated that severity became asymptotic several weeks earlier in fruit development. When mildew-free fruit clusters of $V$. vinifera 'Chardonnay', 'Riesling', 'Gewürztraminer', and 'Pinot Noir' were inoculated at stages ranging from prebloom to 6 weeks postbloom, only fruit inoculated within 2 weeks of bloom developed severe powdery mildew. Substantial ontogenic resistance to infection was expressed in fruit nearly 6 weeks before fruit brix reached $8 \%$ and over 2 months before they

increased steadily over the next 60 days. The rachis of fruit clusters inoculated 31 days after bloom developed only trace levels of powdery mildew. Berry weight of all four cultivars at harvest was reduced when fruit clusters were inoculated at bloom or 16 days postbloom, primarily by splitting, rotting, and dehydration of mildewed berries, but the weight of later-inoculated berries was not reduced. Inoculation of berries just as ontogenic resistance increased markedly, approximately 3 to 4 weeks postbloom, resulted in the development of inconspicuous, diffuse, nonsporulating mildew colonies on berries, sometimes associated with a network of necrotic epidermal cells. Rather than a protracted and relatively static period of berry susceptibility lasting 3 months, fruit of $V$. vinifera appear to acquire ontogenic resistance rapidly after fruit set. A refocusing of disease management on this critical period of high fruit susceptibility should greatly improve the efficacy of fungicides directed against powdery mildew.
\end{abstract} reached $15 \%$. Rachises of 'Chardonnay' and 'Riesling' fruit clusters developed severe powdery mildew when inoculated at bloom, and disease
Additional keyword: Oidium.
Powdery mildew, caused by the fungus Uncinula necator, is one of the most widespread and destructive disease of grapes worldwide. Most cultivars of the European grape (Vitis vinifera), which includes the world's finest and most widely planted wine and table grape cultivars, are highly susceptible to powdery mildew. Some mildew-resistant cultivars have been developed. However, centuries of experience, both in growing cultivars such as 'Chardonnay', 'Riesling', and 'Pinot Noir', and in the making and selling of their wines dictates that vines susceptible to powdery mildew will continue to be grown worldwide (26). For the foreseeable future, powdery mildew will be controlled through the deployment of fungicides, and substantial expenses will be incurred every year in this regard.

Knowledge of the duration and dynamics of fruit susceptibility to infection is critical to the intelligent use of fungicides to manage grapevine powdery mildew. Fruit are reportedly susceptible to infection by $U$. necator until soluble solid levels (brix) reach approximately $8 \%(2,4)$, and established colonies are reported to persist and sporulate until brix reach $15 \%$ (4). These threshold levels of fruit development are widely reported in nearly every textbook, extension bulletin, and fact sheet on management of grape powdery mildew (27) and serve as a basis for decision-making in integrated pest management (IPM) programs $(10,26,34,35)$.

Recently (15), we have found that berries of $V$. labruscana 'Concord' become resistant to powdery mildew approximately 2 weeks after bloom; long before sugar accumulation begins. Further preliminary investigations of ontogenic resistance in fruit of selected V. vinifera 'Chardonnay' and 'Riesling' $(6-9,19)$ indicated that they too became resistant to powdery mildew relatively

Corresponding author: D. M. Gadoury; E-mail address: dmg4@ cornell.edu

Publication no. P-2003-0303-01R

(C) 2003 The American Phytopathological Society early in their development. Similar results were reported recently by Stark-Urnau and Kast (33) for V. vinifera 'Trollinger' and 'Lemberger'. Our objective is to present a more complete explanation of the disparity between the widely used thresholds of 8 to $15 \%$ brix as indicators of berry susceptibility to powdery mildew in $V$. vinifera and the development of ontogenic resistance to $U$. necator under vineyard conditions.

\section{MATERIALS AND METHODS}

Vineyard experiments were conducted in a 1-ha planting of $V$. vinifera 'Chardonnay', 'Riesling', 'Gewürztraminer', and 'Pinot Noir'. The vines were planted in 1974 with $2.4 \mathrm{~m}$ between vines and $2.7 \mathrm{~m}$ between rows, and were Umbrella-Kniffen trained and cane-pruned in each year of the study.

In order to definitively measure the effects of inoculation with $U$. necator at precise stages of fruit development in the vineyard, it was necessary to produce clusters that were both disease-free and free of an effective fungicide residue. This was accomplished by spraying vines with locally systemic fungicides myclobutanil (Nova $40 \mathrm{WP}$ ) at $112 \mathrm{~g} / \mathrm{ha}$ or fenarimol (Rubigan $12 \mathrm{EC}$ ) at $25.2 \mathrm{~g} / \mathrm{ha}$ at 2 -week intervals, from $5 \mathrm{~cm}$ of shoot growth until veraison, and covering selected fruit clusters with small polyethylene bags immediately before the spray applications. The bags were removed within $1 \mathrm{~h}$ after each spray application. The possibility that an effective level of fungicide was present on the bagged clusters following spraying was assessed in a preliminary experiment in 1996 conducted on a separate group of 'Chardonnay' vines within the above vineyard. At the prebloom stage of cluster development, $24 \mathrm{~h}$ after the fungicide application, clusters that had been bagged on both sprayed and unsprayed vines were inoculated with $U$. necator as follows. Conidia were harvested from 14-day-old mildew colonies on $V$. vinifera seedlings by shaking infected leaves in $50 \mathrm{ml}$ of distilled water containing $0.05 \%$ ( $\mathrm{vol} / \mathrm{vol})$ Tween 20. The concentration of the suspension was 
adjusted to a concentration of approximately $10^{5}$ conidia per $\mathrm{ml}$ and was applied within $30 \mathrm{~min}$ of its preparation. The conidial suspension was applied with a hand-held atomizer (Preval Model 268; Precision Valve Corp., Yonkers, NY) until droplets of suspension were visible on the cluster. Five clusters per vine were inoculated, and treatments were replicated on three vines. The percentage of cluster surface colonized was assessed 4 weeks after inoculation. This preliminary experiment was repeated at the fruitset stage of cluster development.

For the purpose of assessing ontogenic resistance, clusters protected from fungicide residues by bagging as previously described were inoculated on the following dates (and stages of cluster development) in the above vineyard: In 1996, on 21 June (10\% bloom), 4 July (2-mm berries), 17 July (4-mm berries), 2 August (4.0 to $4.2 \%$ brix), 15 August (4.5 to $4.8 \%$ brix), and 29 August (7.2 to $9.3 \%$ brix); in 1997, on 24 June (10\% bloom), 10 July (2mm berries), 25 July (3-mm berries), 6 August (4.0\% brix), 21 August (4.8 to $5.6 \%$ brix), and 3 September (9.0 to $12.4 \%$ brix); and in 1998, on 24 June (6 days postbloom), 3 July (4-mm berries), 15 July (4.2 to $4.3 \%$ brix), 30 July (4.2 to $5.4 \%$ brix), and 17 August (9.8 to $11.4 \%$ brix). Clusters to be inoculated were examined on the day of inoculation with a $\times 14$ hand lens to confirm the absence of preexisting powdery mildew colonies. Five mildew-free clusters per vine on three replicate vines per treatment in a completely random design were inoculated as described previously. Responses recorded included the percentage of cluster surface colonized and percentage of rachis surface colonized. Mildew incidence and severity were visually estimated at 14- to 21-day intervals until harvest. The condition of mildew colonies and the berry epidermis on clusters from each treatment were examined at harvest at $\times 35$ magnification.

In each year of the study, brix were measured at 1- to 2-week intervals once berries reached 4-mm diameter. Samples of approximately 60 berries were collected by harvesting four apical berries from approximately five clusters per vine, for each of three vines per treatment replication. The berry samples were crushed and juice soluble solids was measured with a hand-held temperature-compensating refractometer (Model 39-45-01; Bausch and Lomb, Rochester, NY).

The above experiment was conducted on cvs. Chardonnay and Riesling in 1996, and was repeated on 'Chardonnay', 'Riesling', 'Gewürztraminer', and 'Pinot Noir' in 1997; and on 'Gewürztraminer' and 'Pinot Noir' in 1998.

To examine the effect of time of inoculation on reduction of berry weight by powdery mildew in 1997, the 'Pinot Noir' clusters from each treatment in the above study were weighed at harvest, the number of berries per cluster was counted, and the average weight per berry of each cluster was thereby calculated. The experiment was repeated on 'Gewürztraminer', 'Chardonnay', and 'Riesling'.

A general model of relative berry susceptibility at various times after bloom was developed as follows. Distributions of disease severity (Figs. 1 and 2) from 13 to 56 days postbloom were pooled and the maximum of the pooled distribution was set equal to $100 \%$, and other values during the period from 13 to 56 days postbloom were scaled to the maximum of $100 \%$ to express sever-
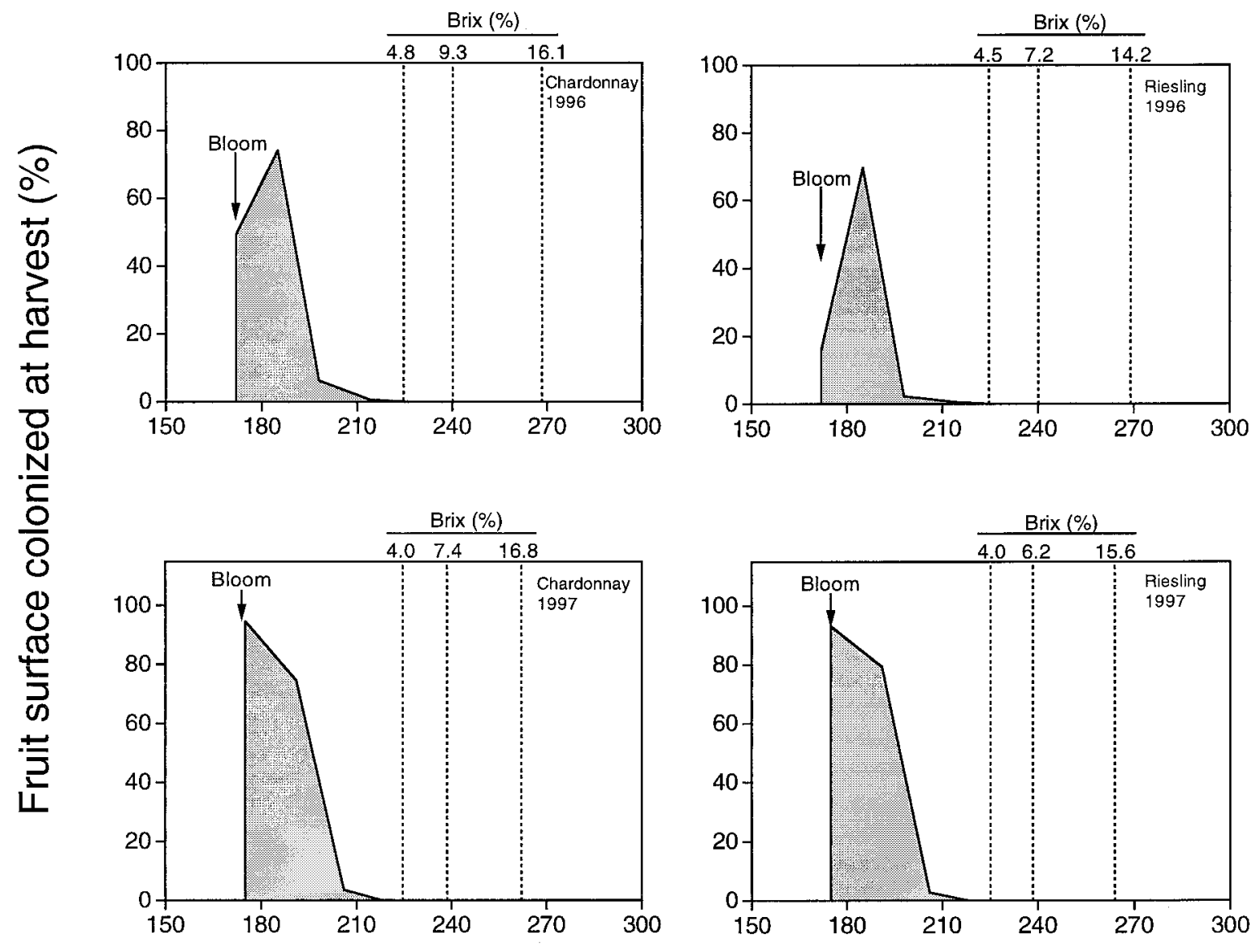

\section{Time of inoculation (day of year)}

Fig. 1. Severity of powdery mildew at harvest on 'Chardonnay' and 'Riesling' fruit inoculated at different stages of growth. Soluble solid levels (brix) in fruit were measured with a refractometer on the indicated days. 
ity on a common relative scale. Both dependent and independent variables were $\log _{10}$-transformed, and linear regression was used to describe the relationship between the relative disease severity at harvest and time of inoculation. This equation was then used to generate predicted daily values for the relative susceptibility of berry clusters during the period from 13 to 56 days postbloom, which were then compared with the relative disease severity values of each individual cultivar-year combination (Figs. 1 and 2 ). Relative susceptibility was set equal to $100 \%$ at times before 13 days postbloom.

To determine the impact of fungicidal protection of berries during a critical period of fruit susceptibility compared with a seasonlong spray program under severe disease pressure, we first thinned the fruit clusters to one cluster per shoot approximately 10 days before bloom, and then inoculated the leaf opposite the remaining mildew-free cluster (confirmed by inspection of cluster with a $\times 14$ hand lens) with a suspension of $10^{5}$ conidia per $\mathrm{ml}$. The cluster was bagged during inoculation of the opposite leaf, and the spore suspension was allowed to dry on the opposite leaf for $1 \mathrm{~h}$ before the bag was removed from the cluster. The objective was to create and maintain sporulating mildew colonies on leaves adjacent to developing fruit clusters subjected to different periods of fungicidal protection. The leaves of selected shoots were bagged during fungicide applications, and fungicides were sprayed directly on the cluster with a hand-held atomizer (Preval Model 268; Precision Valve Corp.) until droplets were visible. Three different fungicide treatments were assigned randomly to five shoots on each of three replicate vines in 2000, and the experiment was repeated in 2001: (i) clusters unsprayed for the entire growing season; (ii) clusters sprayed with $120 \mathrm{mg}$ active ingredient (a.i.) kresoxim-methyl (Sovran 50W, BASF Corp.) per liter at bloom and again 10 days later; or (iii) clusters sprayed with $50 \mathrm{mg}$ a.i. fenarimol (Rubigan 1EC) per liter at $15-\mathrm{cm}$ shoot growth and again 10 days later (prebloom), with $120 \mathrm{mg}$ a.i. kresoxim-methyl per liter at bloom (10 days after the second fenarimol application) followed by $120 \mathrm{mg}$ of kresoxim-methyl per liter at two subsequent 10-day intervals, and then with $5.0 \mathrm{~g}$ of wettable sulfur per liter at four additional 10-day intervals thereafter. The latter treatment approximated a commercial spray program for control of powdery mildew on 'Chardonnay' in New York State. Mildew colonies were macroscopically visible on the upper surface of all inoculated leaves within 7 days, and sporulation was confirmed in some of the colonies using a $\times 14$ hand lens within 10 days after inoculation in both years of the study.

\section{RESULTS}

There was no effective fungicide residue on clusters that were bagged during fungicide applications of the preliminary experiments conducted in 1996. Four weeks after inoculation of 'Chardonnay' clusters at prebloom, there was no significant $(P=0.05$, Student's $t$ test) difference in the severity of powdery mildew that developed on clusters that were bagged during spraying $(52.3 \%$, $\mathrm{SE}=4.91)$ versus clusters that were inoculated on unsprayed control vines $(49.8 \%, \mathrm{SE}=5.04)$. Similarly, there was no significant difference between the severity of mildew that developed 4 weeks
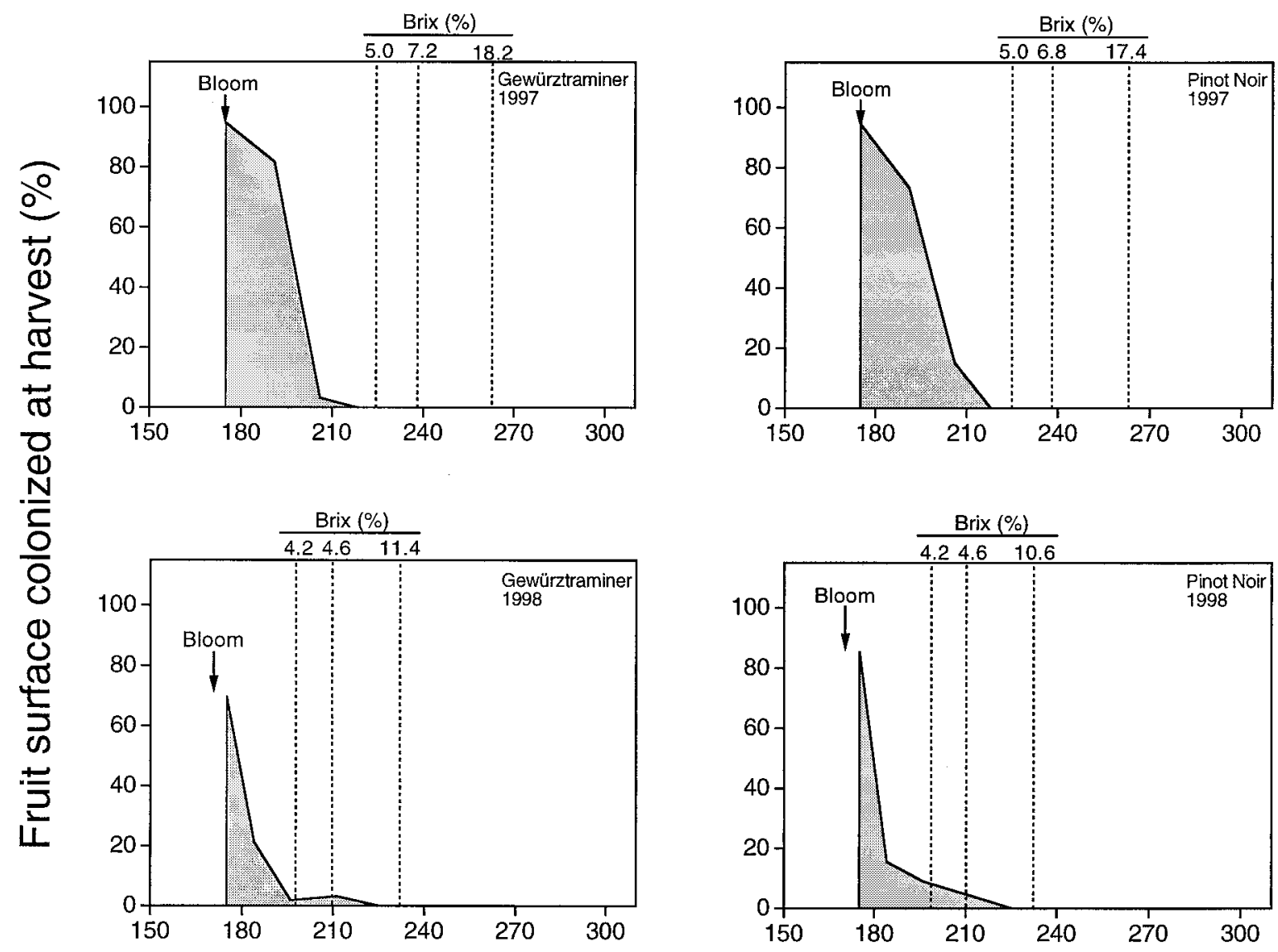

\section{Time of inoculation (day of year)}

Fig. 2. Severity of powdery mildew at harvest on 'Gewürztraminer' and 'Pinot Noir' fruit inoculated at different stages of growth. Soluble solid levels (brix) in fruit were measured with a refractometer on the indicated days. 
after inoculation on sprayed $(47.7 \%, \mathrm{SE}=3.53)$ versus unsprayed $(46.0 \%, \mathrm{SE}=2.98)$ vines when the experiment was repeated at fruit set.

Berries on all cultivars inoculated at $10 \%$ bloom and at fruit set in 1996 and 1997, or inoculated at fruit set in 1998, developed severe disease by harvest (Figs. 1 and 2). However, within 3 to 4 weeks after bloom, fruit appeared to be nearly immune to infection (Figs. 1 and 2). Fruit rapidly acquired substantial ontogenic

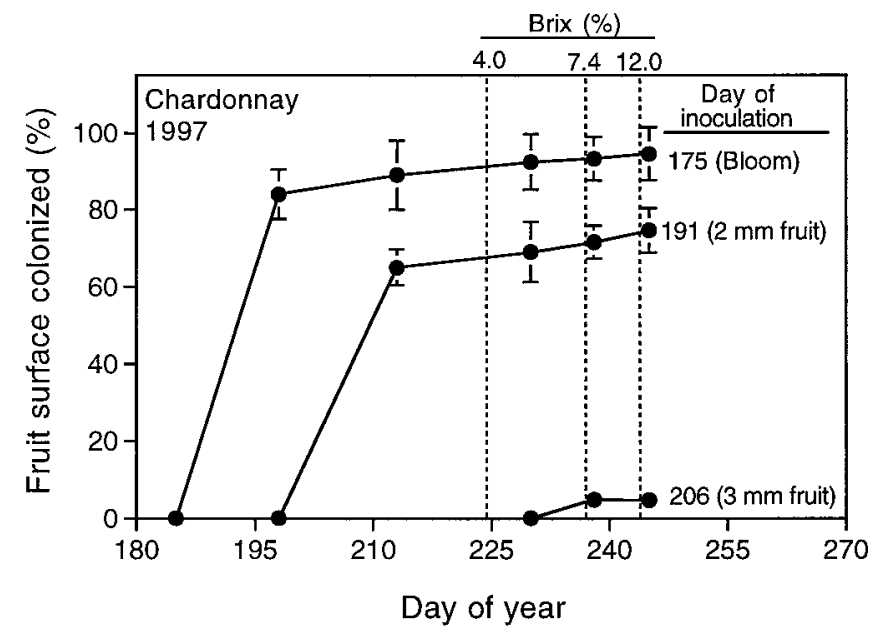

Fig. 3. Progress of powdery mildew on 'Chardonnay' grapes inoculated at three stages of development. Soluble solid levels (brix) in fruit were measured with a refractometer on the indicated days. Bars indicate one standard error of the mean.

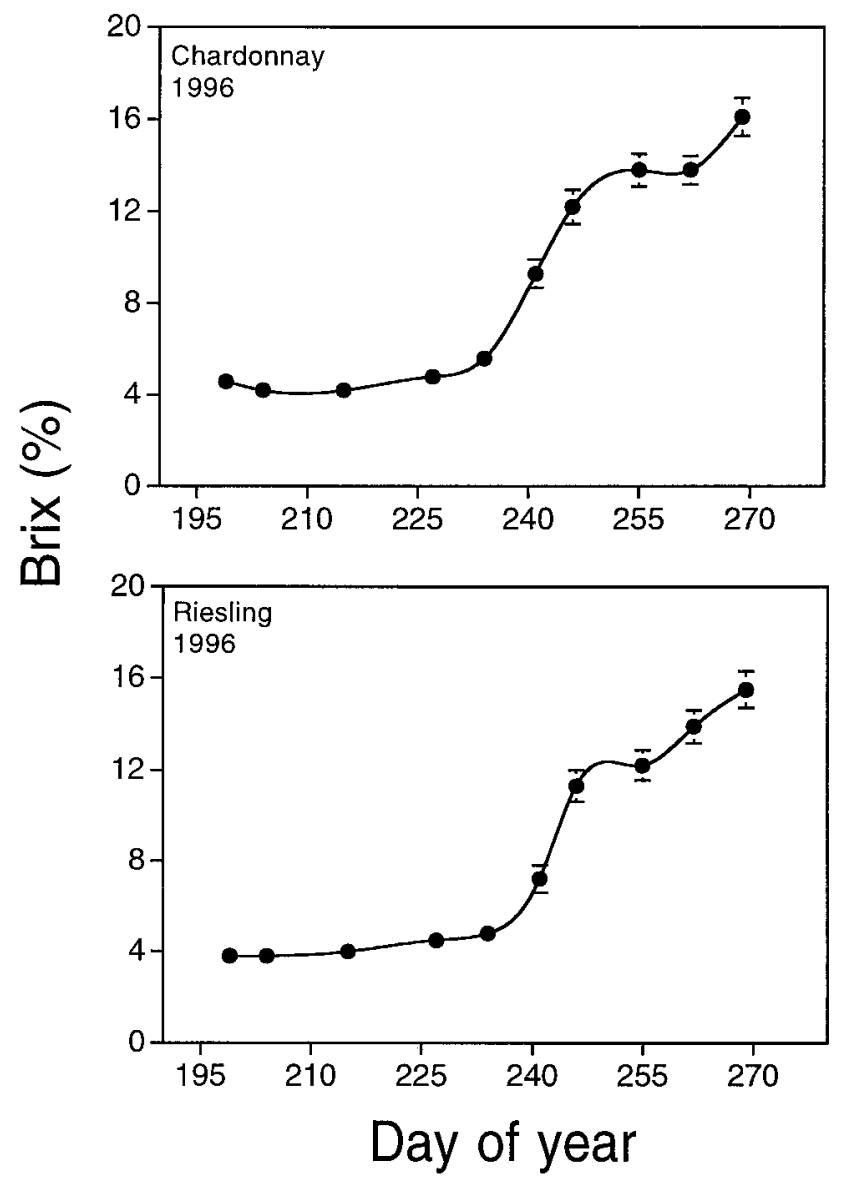

Fig. 4. Accumulation of soluble solids (brix) in fruit of 'Chardonnay' and 'Riesling' grapevines in 1996. Bars indicate one standard error of the mean. resistance after bloom. There was no marked difference in the temporal distributions of susceptibility between cultivars or years, with the exception of those for 'Pinot Noir' and 'Gewürztraminer' in 1998 (Fig. 2), when the first inoculation was applied 6 days postbloom rather than at $10 \%$ bloom (Figs. 1 and 2), thereby truncating the distribution. Nonetheless, in all cultivar-year combinations, fruit passed from highly susceptible to nearly immune in less than 30 days (Figs. 1 and 2).

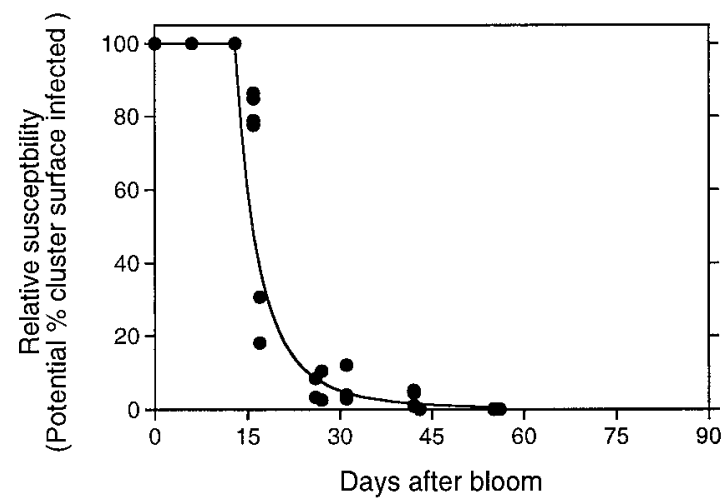

Fig. 5. Predicted (line) and observed (data points) relative susceptibility to powdery mildew. Predicted susceptibility was generated by a regression equation fit to a distribution developed from pooled disease severity observed when grapes were inoculated at various stages of development during 1996 to 1998 . Relative severity was set equal to $100 \%$ at times before 13 days postbloom, and subsequent severity was scaled such that the maximum of the distribution of each cultivar-year combination was $100 \%$ before the data were pooled.

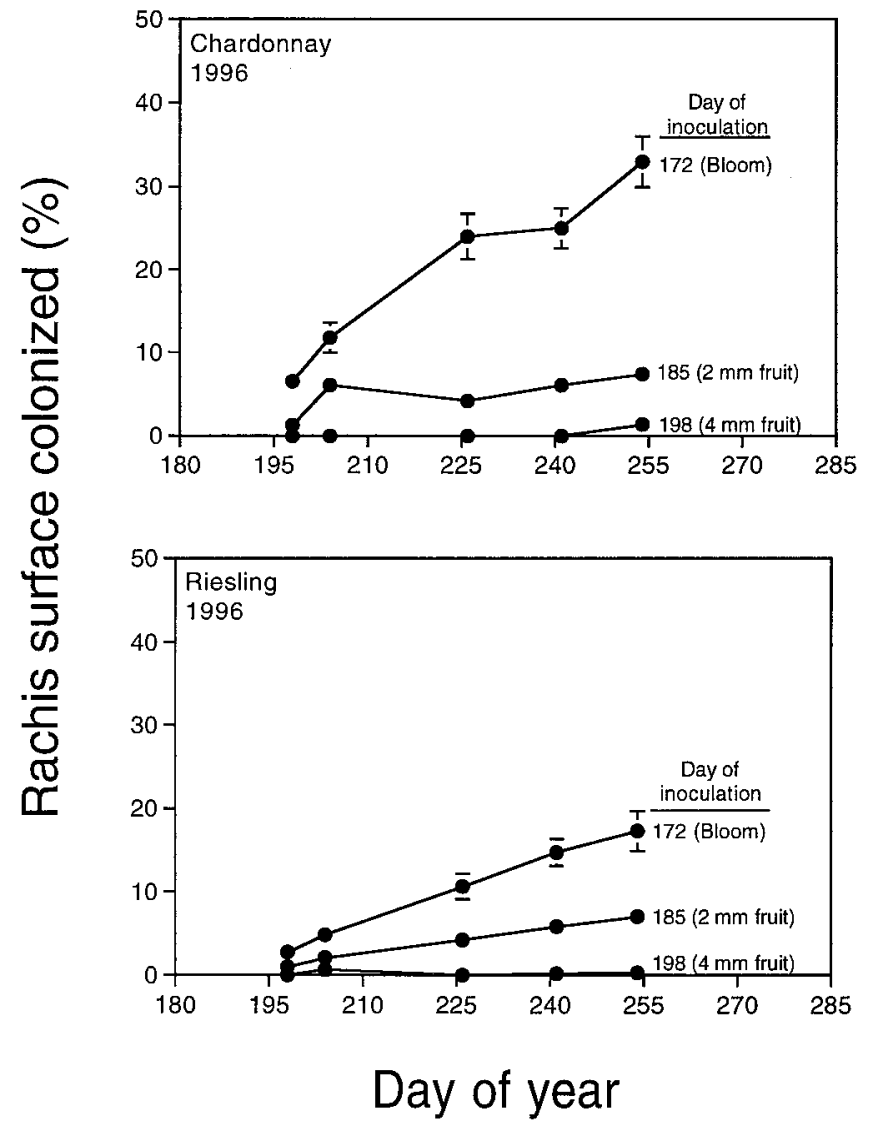

Fig. 6. Progress of powdery mildew on the rachis of 'Chardonnay' and 'Riesling' grapes inoculated at different stages of fruit development in 1996. Bars indicate one standard error of the mean. 
Once ontogenic resistance was strongly expressed, at approximately 3 to 4 weeks after bloom, disease progress, measured as the percentage of berry surface visibly colonized, effectively ceased (Fig. 3). The percentage of cluster surface colonized for the period from 21 days postinoculation to harvest was regressed against time using simple linear regression for clusters inoculated at bloom, 2-mm fruit, or 3-mm fruit. The slope coefficients during this period were not significantly different from zero for each cultivar-year combination $(P=0.05)$.

Accumulation of soluble solids (percent brix) in berries was not related to the onset or accelerated development of ontogenic resistance. Brix levels in 'Chardonnay' and 'Riesling' berries in 1996 were near or below $4 \%$ for approximately 60 days after bloom (Fig. 4), or approximately 30 days after fruit were apparently immune to infection (Figs. 1 and 2). Ontogenic resistance was strongly expressed in all other cultivar-year combinations before brix levels reached 5\% (Figs. 1 and 2). Brix did not reach $8 \%$, a previously reported threshold for infection $(2,4)$, until 55 to 70 days postbloom (Figs. 1, 2, and 4), and did not reach 15\%, a previously reported threshold for cessation of sporulation in existing colonies (4), until nearly 100 days postbloom (Figs. 1, 2, and 4).

The linear regression (REGRESS, Minitab 10.5 Xtra, Minitab Inc., State College, PA) fit to the pooled distribution of relative disease severity was $Y=5.962-3.557 X$, where $Y=\log _{10}$ of the relative disease severity (percent), and $X=\log _{10}$ of days after bloom for the period ranging from 13 to 56 days postbloom; $R^{2}=$ $97.9 \%$, and SD (standard deviation of the regression) $=0.129$.

Setting values of relative disease severity equal to $100 \%$ at times before 13 days postbloom approximated a step-function, and subsequent relative susceptibility of clusters predicted by the regression equation accurately modeled observed susceptibility from bloom to 56 days postbloom, i.e., until berries were immune to infection (Fig. 5). Values for predicted relative susceptibility of clusters for $13,14,15,16,17,18,20,22,25,30,35,40,50$, and
55 days after bloom were 99.9, 76.8, 60.1, 47.8, 38.5, 31.4, 21.6, 15.4, 9.8, 5.1, 2.95, 1.83, 0.83, and 0.55\%, respectively (Fig. 5).

The susceptibility of the rachis of 'Chardonnay' and 'Riesling' clusters decreased with age (Fig. 6). The rachis of clusters inoculated when berries were $4 \mathrm{~mm}$ in diameter, 26 days postbloom, bore only trace levels of powdery mildew at harvest (Fig. 6). Disease increased throughout the summer on rachis of clusters inoculated at bloom (Fig. 6) rather than halting approximately 30 days postbloom as was observed on berries (Fig. 3).

Berry weight was significantly decreased by powdery mildew when berries were inoculated before ontogenic resistance was strongly expressed and they became heavily colonized by the pathogen (Fig. 7). However, once berries reached 3-mm diameter (28 days postbloom), inoculations resulted in little powdery mildew development and there was no associated decrease in berry weight (Fig. 7). Loss of berry weight was primarily due to splitting, rotting, and mummification of berries that were severely diseased (Fig. 8A). Although colonized calyptra (Fig. 8B) were shed during bloom, mildew colonies simultaneously present on the pedicel expanded onto the berry within days after anthesis (Fig. 8C) and rapidly spread over the berry surface (Figs. 3 and $8 \mathrm{C}$ ). Nearly all clusters inoculated 28 to 30 days postbloom were apparently mildew-free in vineyard assessments (Figs. 1, 2, and $8 \mathrm{~A}$ ). However, close examination of berry surfaces at $\times 30$ to $\times 50$ magnifications using intense lateral illumination revealed a diffuse network of nonsporulating hyphae closely appressed to the epidermis (Fig. 8D and E). This diffuse colonization covered up to $30 \%$ of the surface of infected berries and was observed on up to $50 \%$ of the berries in clusters inoculated at the above stage of development. Diffuse colonization by $U$. necator was often associated with patches of necrotic epidermal cells and russeting of the berry epidermis at the sites of appressorium formation along hyphal strands (Fig. 8D and E). In contrast to uninfected epidermal tissue (Fig. 8F), the cuticle was often discontinuous at such sites, in
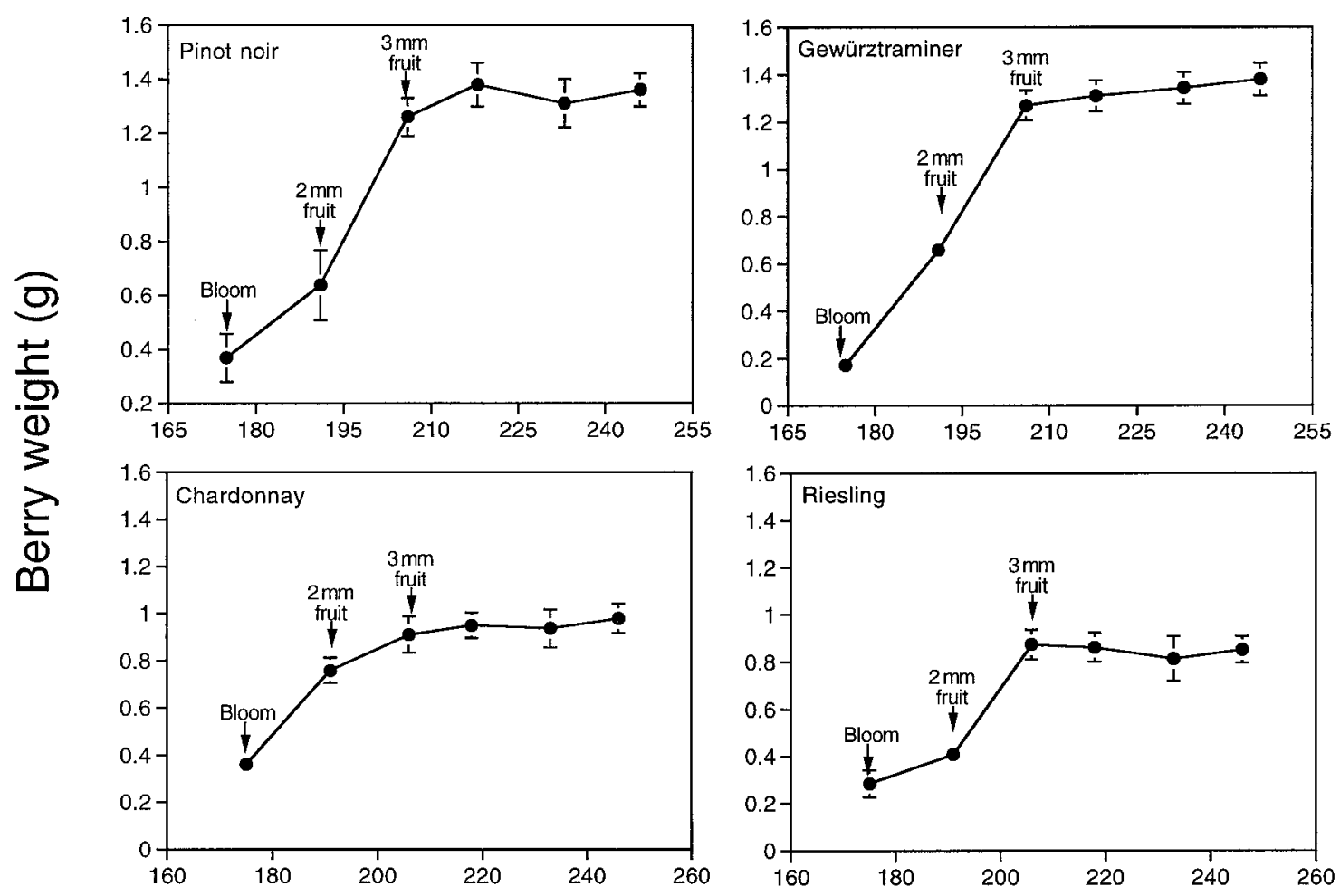

\section{Time of inoculation (day of year)}

Fig. 7. Effect of powdery mildew on weight of berries at harvest in 1997. Clusters of each cultivar were inoculated at different stages of fruit development. Bars indicate one standard error of the mean. 


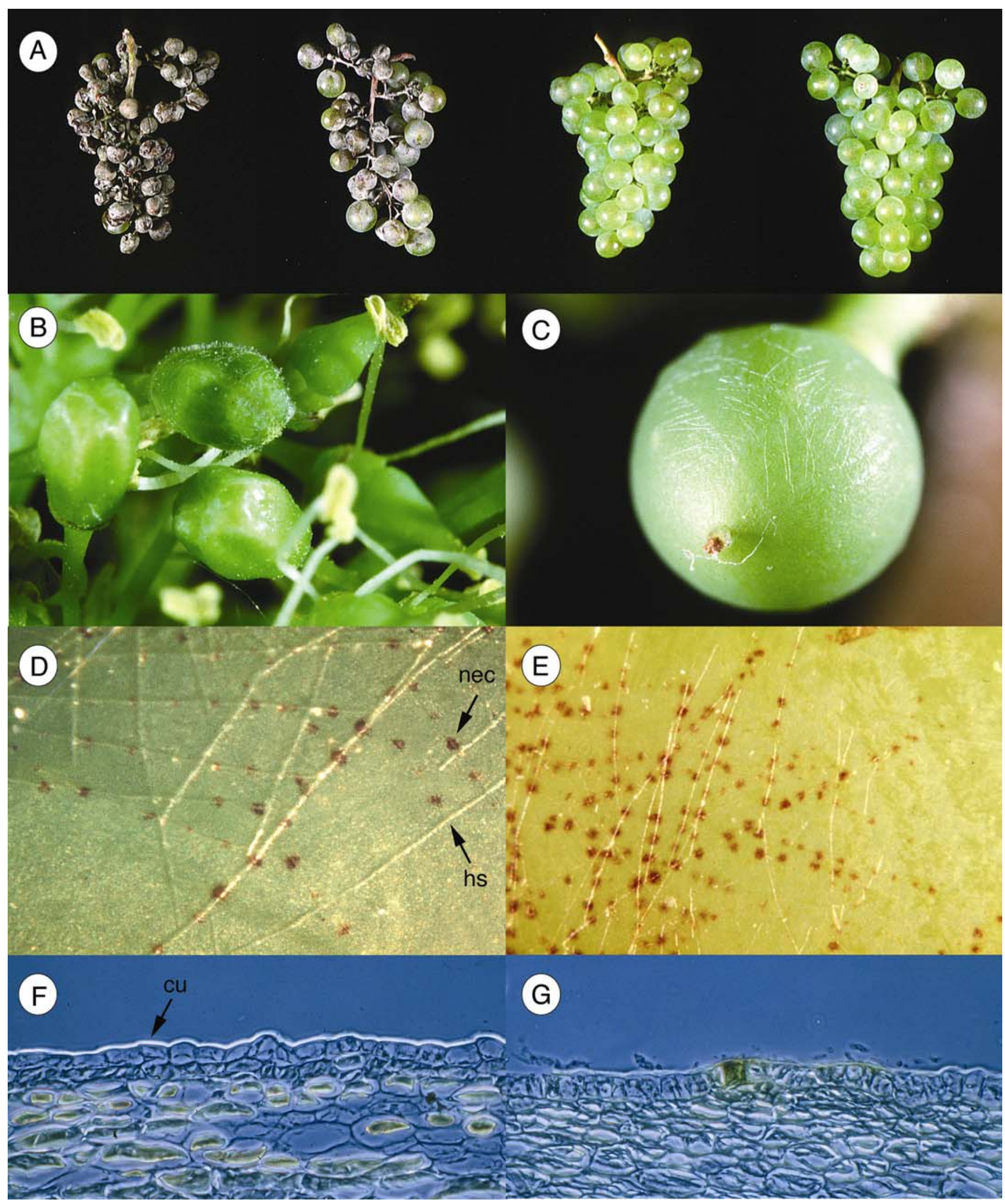

Fig. 8. Development of Uncinula necator on grape berries. A, Clusters of 'Chardonnay' grapes inoculated with conidia of U. necator (from left) at $10 \%$ bloom, 2-mm fruit, and 3 and 8 weeks postbloom. Note that the cluster inoculated at 3 weeks postbloom, although macroscopically disease-free, bore diffuse powdery mildew colonies on over $30 \%$ of the berries. B, Early colony development on calyptra of 'Chardonnay' cluster inoculated at $10 \%$ bloom. C, Nonsporulating young mildew colony on 1-week-old 'Chardonnay' berry from cluster inoculated at 10\% bloom, photographed 5 days after complete anthesis in cluster. $\mathbf{D}$ and E, Eight-week-old, nonsporulating, diffuse powdery mildew colonies on 'Chardonnay' berries inoculated at 3 weeks postbloom. nec $=$ necrotic epidermal cells; hs $=$ hyphal strand. Diameter of necrotic areas from approximately 10 to $50 \mu \mathrm{m}$. F, Cross section from uninoculated 'Chardonnay' berry at 8 weeks postbloom photographed under phase-contrast microscopy. cu = cuticle. G, Cross section of 'Chardonnay' berry inoculated at 3 weeks postbloom showing discontinuous cuticle and necrotic epidermal cells within diffuse powdery mildew colony. 
particular where single epidermal cells or small groups of cells had died (Fig. 8G).

Two fungicide sprays applied 10 days apart beginning at bloom provided nearly complete control of powdery mildew on 'Chardonnay' fruit despite the presence of sporulating mildew colonies on leaves that had been inoculated approximately 10 days earlier adjacent to the fruit clusters (Fig. 9). Six additional fungicide sprays applied before and after this period did not provide additional disease control on fruit (Fig. 9).

\section{DISCUSSION}

Ontogenic resistance was strongly expressed in berries of four $V$ vinifera cultivars within 20 days after bloom in each year of our study. This is slightly longer than the period of fruit susceptibility that we found in a recent study (15) on V. labruscana 'Concord', which is generally regarded as only moderately susceptible to powdery mildew; however, ontogenic resistance was strongly expressed much sooner than is widely reported for $V$. vinifera $(2,4,10,26,27,34,35)$. Previously suggested mechanisms for this phenomenon, such as accumulation of soluble solids in nearly mature fruit and the consequent changes in osmotic potentials $(2,4,31)$, or constitutive synthesis of compounds with antimicrobial activity coincident with veraison (30) therefore may not be causally linked to ontogenic resistance, because ontogenic resistance results in near immunity to infection which precedes these processes by several weeks.

Our results do not support the widespread $(10,26,27,34,35)$ use of a developmental threshold of 8 to $15 \%$ brix to denote when fruit become resistant to powdery mildew. One possible explanation for the disparity between our findings and earlier reports may be that at least two previous studies $(2,4)$ used only detached fruit as a substrate for pathogen growth. It is possible that detachment from the vine has some effect on the normal maturation process, and hence may affect the development of ontogenic resistance. Although detached fruit may be appropriate to study factors such as infection efficiency, in which data are collected within hours after fruit detachment, they seem less appropriate for longer term studies such as the development of disease on an organ in which maturation may have been greatly slowed or halted. The recent study by Stark-Urnau and Kast (33), in which fruit of cvs. Trollinger and Lemberger were left attached to the vine, yielded distributions of ontogenic resistance very similar to those reported in our study.

The disparity between our observations of relatively early development of ontogenic resistance to powdery mildew and the later development reported elsewhere also might be partially due to the temporal lag between inoculation and the development of conspicuous symptoms under vineyard conditions. Colonization of berries rarely became obvious to the naked eye until 2 or more weeks after inoculations in our study, and the delay of conspicuous disease became even more pronounced as fruit matured. Our results indicate that irrespective of when symptoms are conspicuously expressed, and therefore observed in surveys of a vineyard, severe powdery mildew on fruit is a consequence of infection early in the development of fruit, i.e., prebloom until 2 to 3 weeks postbloom. Fruit are nearly immune to infection long before brix levels reach $8 \%$.

Substantial differences have been reported in the incidence and severity of powdery mildew among numerous cultivars of $V$. vinifera $(1,5,26,27)$, and differences in general resistance of the cultivars to powdery mildew has been inferred from these reports. However, the absolute levels of disease severity obtained among four cultivars of diverse parentage (28), as well as the distributions of fruit susceptibility through time were similar under the experimental conditions of the present study. Similarly, Gadoury and Pearson (14) found no differences in pathogenicity or virulence among a collection of 35 clonal isolates of $U$. necator iso- lated from several Vitis spp. when grown on $V$. vinifera seedlings, i.e., all were highly aggressive on seedlings derived from 'Riesling' grapes. Among the four cultivars investigated by us, significant differences in susceptibility to powdery mildew, as observed in other studies, are possibly due to factors other than differential virulence in the pathogen population, differential susceptibility of juvenile tissues, or the shape or amplitude of the temporal distribution of ontogenic resistance in developing berries. Our ongoing investigations indicate that both anatomical and biochemical responses in developing fruit may be involved in reducing infection efficiency and longevity of $U$. necator germlings on the epidermis of ontogenically resistant fruit (6-9).

The pooling of our data to develop a general model of the development of ontogenic resistance illustrates just how quickly fruit change from highly susceptible to highly resistant organs. In as little as 2 weeks, predicted (and observed) fruit susceptibility exponentially declined from its maximum to near-minimum (Fig. 5). Disease progress curves obtained for 'Chardonnay' and 'Riesling' fruit (Fig. 3) also show a plateau in disease development once ontogenic resistance to infection is strongly expressed. Although the time variable used in the model was days after bloom, it may be possible to adapt the model to other climatic regions by expressing the independent variable as degree-days to account for warmer or cooler prevailing weather during early vine growth. We are presently collecting phenology and temperature data from several cooperators in the United States, Europe, and Australia to attempt this adaptation. One potentially important factor that is not accounted for in our analysis is the increased temporal heterogeneity in phenology that may be observed in warmer viticultural regions. In New York, 50\% bloom within a vineyard is a discrete event that typically is completed within 1 to 2 days. In warmer regions, bloom of a vineyard may take place over a longer period of time (20). Although an individual cluster may complete bloom more rapidly at higher versus lower daily temperatures, the population of fruit clusters on a single day may consist of several cohorts ranging from several days prebloom to several days postbloom. Temporal heterogeneity in phenology, and the environmental factors that exacerbate it, are poorly understood phenomena, but any factor that inflated the variation in bloom date would

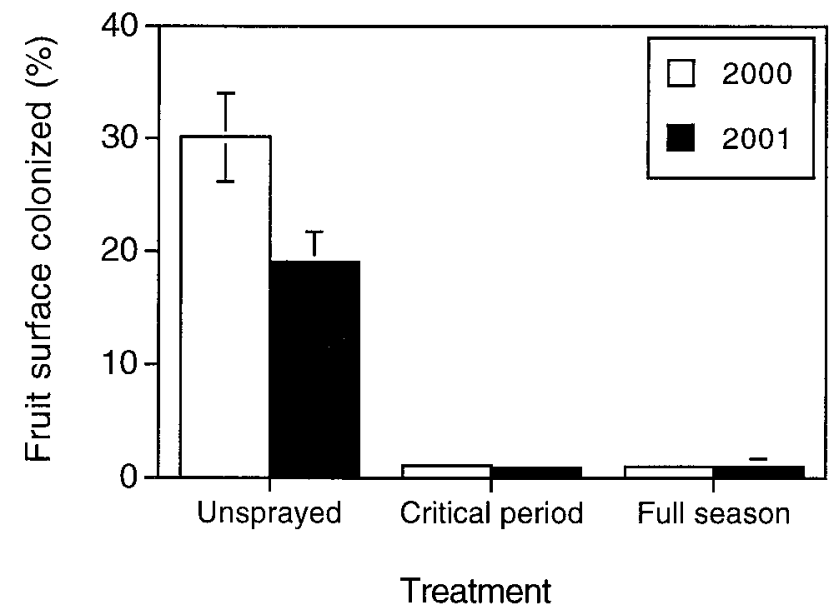

Fig. 9. Degree of disease suppression afforded by two fungicide sprays applied during a critical period of fruit susceptibility (bloom to 20 days postbloom) compared with a full-season program of eight fungicide applications in 2000 and 2001. The leaves of a shoot were inoculated with a spore suspension of Uncinula necator approximately 10 days before bloom. Fruit clusters were not inoculated, and were hand sprayed with fungicides with an atomizer, whereas foliage was protected during fungicide applications by bagging to create and maintain sporulating mildew colonies on unsprayed leaves adjacent to developing fruit clusters subjected to different periods of fungicidal protection. The control was inoculated but not sprayed with fungicides. Bars indicate one standard error of the mean. Means without visible error bars had standard errors that approached zero. 
create the appearance of a more protracted period of fruit susceptibility. We are presently investigating how we can better predict climate-based temporal heterogeneity in phenology, how heterogeneity affects the distribution of ontogenic resistance, and the consequent risk of disease. Although we are presently concerned with powdery mildew, the results may equally apply to other diseases in which phenology affects susceptibility to infection; e.g., black rot (Guignardia bidwellii) (21), downy mildew (Plasmopara viticola) (22), Botrytis bunch rot (Botrytis cinerea) (27), and Phomopsis fruit rot (Phomopsis viticola) (29). Susceptibility to all of the aforementioned diseases is linked to key phenological stages during which susceptibility to infection is maximal. Therefore, increased temporal heterogeneity in phenology could likewise extend the period during which the crop is at risk.

In previous studies $(15,17,18)$, we had reported that severe infection of fruit on unsprayed grapevines was associated with years during which there was an above-average number of rain events near the time of bloom. Given that the ascospores are discharged during rain events between bud break and shortly after bloom in many viticultural areas $(3,11,12,24,25,32)$, the favorability of such years for fruit infection may be directly attributable to the occurrence of multiple ascosporic infection periods $(12,13)$ during the peak period of fruit susceptibility.

In a recent study (15) of the epidemiology of powdery mildew on V. labruscana 'Concord', we noted that the rachis was possibly the most susceptible organ of the 'Concord' vine and retained a high level of susceptibility until shortly before harvest, when a periderm layer formed on the berry stem, effectively killing the pathogen. In contrast, the rachis of 'Chardonnay' and 'Riesling' appeared to become resistant by the time fruit were $2 \mathrm{~mm}$ in diameter, or 13 days after bloom (Fig. 6), even though the onset of periderm formation in these cultivars does not precede that of 'Concord'. Additionally, we never observed severe rachis infection on 'Pinot Noir' and 'Gewürztraminer' clusters inoculated more than 2 weeks after bloom. Therefore, despite the relatively (compared with 'Concord') higher incidence and severity of berry infection commonly observed on the four $V$. vinifera cultivars used in the present study, the rachis appears to acquire substantial ontogenic resistance to infection at approximately the same time as the developing young fruit. However, ontogenic resistance in the rachis was less effective against the increase of disease severity at 3 to 12 weeks after bloom when rachis infection was initiated at bloom (Fig. 6). Unlike berries, prior colonization of the rachis of 'Chardonnay' and 'Riesling' conferred some advantage for continued growth of the pathogen.

In 'Concord', prebloom infection of the rachis was an important avenue for spread of the pathogen to the developing fruit (15). Infected calyptra were shed during bloom and probably did not contribute to disease on fruit (15). Once established on the rachis, hyphae quickly traversed the gap between the pedicel and the ovary wall immediately after anthesis and thereby spread to the epidermis of the young berry (15). We observed a similar pattern of spread on the $V$. vinifera cultivars of the present study within 3 days after bloom when clusters were inoculated before bloom (Fig. 8), and it is likely that this describes the general pattern of spread to developing fruit when $U$. necator is established at prebloom on the rachis.

Although fruit became highly resistant to infection within 3 to 4 weeks after bloom, fruit inoculated at that time were not disease-free at harvest but rather had developed diffuse and macroscopically invisible powdery mildew colonies. We have since discovered that these inconspicuous diffuse colonies predispose fruit of many cultivars to bunch rots, can lead to the development of high population densities of spoilage microorganisms on fruit with diffuse powdery mildew, and can degrade wine quality if wine is made from berries with diffuse powdery mildew (16). Management programs for powdery mildew are generally developed from field studies that yield fruit that appear to be disease-free. Sup- pression of only apparent disease and the failure to control diffuse infections may not produce fruit, and consequently wine, of the highest quality. Management of powdery mildew for optimal production of wine grapes may require extending fungicidal protection beyond a point where any reduction of disease can be observed in routine field assessments. Although it may seem wasteful to treat grapes for powdery mildew without a visible reduction of symptoms, extending intensive management until the fruit are completely resistant to infection (i.e., infections must be prevented until 4 weeks postbloom under the conditions of our study) will avoid diffuse infections and the associated reduction of crop quality.

The strategic refocusing of disease management based on forecasts of ontogenic resistance can have several practical impacts upon IPM programs. Management of resistance risk in fungicides is generally enhanced by (i) maximal rates of applications, (ii) minimal intervals between applications, and (iii) minimal numbers of applications (23). Frequency and rate of application of the most efficacious, but often most resistance-prone materials (e.g., strobilurin and sterol demethylation inhibiting compounds), could be optimized to produce the best possible outcome for their effective and sustainable use. Less efficacious, but often less expensive, and resistance-free compounds (e.g., sulfur or fungicidal oils) could be used to address foliar powdery mildew outside the period of maximum fruit susceptibility.

Preservation of the health of the vine canopy is an integral and necessary part of managing powdery mildew $(15,18,26)$. However, canopy health adds little economic value to the crop if the fruit are diseased. We were able to control powdery mildew on fruit with only two fungicide applications that were timed to cover the period of peak fruit susceptibility. Additional sprays applied before and after the critical period did not improve disease control on fruit. The level of disease created in this trial was far above what would be expected in a commercial vineyard (17). Wilcox and Riegel (36) obtained a similar outcome for the Vitis interspecific hybrid cv. Rosette in a trial that focused fungicide applications on the aforementioned peak period of fruit susceptibility. Absent resistance in the pathogen population, and given a thorough application, relatively few fungicide applications may be responsible for the outcome of a disease management program with respect to fruit infection. Conversely, improper selection of materials or misapplication during the critical period of fruit susceptibility is unlikely to be offset by prior or subsequent actions. We are hopeful that continuing work will allow more focused and effective fungicide spray programs based on regionally adapted models of ontogenic resistance to be extended to areas outside the northeastern United States.

\section{ACKNOWLEDGMENTS}

This research was supported by the USDA/FAS/OICD/RSED competitive grants program, by the USDA Viticulture Consortium, the New York Wine and Grape Foundation, The Grape Production Research Fund, The Lake Erie Regional Grape Program, and the Kaplan Fund. We thank A. Day, D. Riegel, R. Weinstock, and S. Culver for their dedication and talent.

\section{LITERATURE CITED}

1. Chellemi, D. O., and Marois, J. J. 1991. Sporulation of Uncinula necator on grape leaves as influenced by temperature and cultivar. Phytopathology 81:197-201.

2. Chellemi, D. O., and Marois, J. J. 1992. Influence of leaf removal, fungicide applications, and fruit maturity on incidence and severity of grape powdery mildew. Am. J. Enol. Vitic. 43:53-57.

3. Cortesi, P., Bisiach, M., Ricciolini, M., and Gadoury, D. M. 1997. Cleistothecia of Uncinula necator are an additional source of inoculum in Italian vineyards. Plant Dis. 81:922-926.

4. Delp, C. J. 1954. Effect of temperature and humidity on the grape powdery mildew fungus. Phytopathology 44:615-626. 
5. Doster, M. A., and Schnathorst, W. C. 1985. Effects of leaf maturity and cultivar resistance on development of the powdery mildew fungus on grapevines. Phytopathology 75:318-321.

6. Ficke, A., Gadoury, D. M., Seem, R. C., and Dry, I. B. 1999. Pathogen development and host response during infection of grape berries by $\mathrm{Un}$ cinula necator. (Abstr.) Phytopathology 89(suppl.):S25.

7. Ficke, A., Gadoury, D. M., Seem, R. C., and Dry, I. B. 2003. Effects of ontogenic resistance upon establishment and growth of Uncinula necator on grape berries. Phytopathology 93:556-563.

8. Ficke, A., Gadoury, D. M., Seem, R. C., Goffinet, M., and Dry, I. B. 2000. Anatomical responses in grape berries to infection by Uncinula necator. (Abstr.) Phytopathology 90(suppl.):S24.

9. Ficke, A., Gadoury, D. M., Seem, R. C., Goffinet, M. C., and Dry, I. B. 2001. Characterization of potential host barriers to Uncinula necator in developing grape berries. (Abstr.) Phytopathology 91(suppl.):S28.

10. Flaherty, D. L., Jensen, F. L., Kasimatis, A. N., Kido, H., and Moller, W. J. (eds.) 1982. Grape Pest Management. Univ. Calif. Publ. 4105.

11. Gadoury, D. M., and Pearson, R. C. 1988. Initiation, development, dispersal, and survival of cleistothecia of Uncinula necator in New York vineyards. Phytopathology 78:1413-1421.

12. Gadoury, D. M., and Pearson, R. C. 1990. Ascocarp dehiscence and ascospore discharge in Uncinula necator. Phytopathology 80:393-401.

13. Gadoury, D. M., and Pearson, R. C. 1990. Germination of ascospores and infection of Vitis by Uncinula necator. Phytopathology 80:11981203.

14. Gadoury, D. M., and Pearson, R. C. 1991. Heterothallism and pathogenic specialization in Uncinula necator. Phytopathology 81:1287-1293.

15. Gadoury, D. M., Seem, R. C., Ficke, A., and Wilcox, W. F. 2001. The epidemiology of powdery mildew on Concord grapevine. Phytopathology 91:948-955.

16. Gadoury, D. M., Seem, R. C., Ficke, A., Wilcox, W. F., and HenickKling, T. 2000. Diffuse infections of Uncinula necator predispose grape berries to bunch rot and spoilage microorganisms, and degrade wine quality. (Abstr.) Phytopathology 90(suppl.):S26.

17. Gadoury, D. M., Seem, R. C., Magarey, P. A., Emmett, R., and Magarey, R. 1997. Effects of environment and fungicides on epidemics of grape powdery mildew: Considerations for practical model development and disease management. Vitic. Enol. Sci. 52:225-229.

18. Gadoury, D. M., Seem, R. C., Pearson, R. C., Wilcox, W. F., and Dunst, R. M. 2000. Effects of powdery mildew on vine growth, yield, and quality of Concord grapes. Plant Dis. 85:137-140.

19. Gadoury, D. M., Seem, R. C., and Wilcox, W. F. 1998. The early development of ontogenic resistance to powdery mildew in fruit of Vitis labruscana and Vitis vinifera grapevines. Page 36 in: Proc. Int. Workshop on Grapevine Downy and Powdery Mildew, 3rd. SARDI Res. Rep. Ser. No. 22, Adelaide, Australia.

20. Gladstones, J. S. 1992. Viticulture and Environment. Winetitles, Adelaide, Australia.
21. Hoffman, L. E., Wilcox, W. F., Gadoury, D. M., and Seem, R. C. 2002. Influence of grape berry age on susceptibility to Guignardia bidwellii and its incubation period length. Phytopathology 92:1068-1076.

22. Kennelly, M. M., Seem, R. C., Gadoury, D. M., Wilcox, W. F., and Magarey, P. A. 2001. Ontogenic resistance to Plasmopara viticola in grape berries. (Abstr.) Phytopathology 91(suppl.):S47.

23. Köller, W. 1995. Managing resistance to sterol demethylation inhibitors. Pages 340-349 in: ACS Conf. Proc. Series; 8th Int. Congr. Pesticide Chem. Options 2000. American Chemical Society, Washington, DC.

24. Magarey, P. A., Gadoury, D. M., Emmett, R. W., Biggins, L. T., Clarke, K., Wachtel, M. F., Wicks, T. J., and Seem, R. C. 1997. Cleistothecia of Uncinula necator in Australia. Vitic. Enol. Sci. 52:210-218.

25. Pearson, R. C., and Gadoury, D. M. 1987. Cleistothecia, the source of primary inoculum for grape powdery mildew in New York. Phytopathology 77:1509-1514.

26. Pearson, R. C., and Gadoury, D. M. 1992. Grape powdery mildew. Pages 129-146 in: Plant Diseases of International Importance. Vol. 3, Diseases of Fruit Crops. J. Kumar, H. S. Chaube, U. S. Singh, and A. N. Mukhopadhyay, eds. Prentice Hall, Englewood Cliffs, NJ.

27. Pearson, R. C., and Goheen, A. C. 1988. Compendium of Grape Diseases. The American Phytopathological Society, St. Paul, MN.

28. Pool, R. M., Einset, J., Kimball, K. H., Watson, J. P., Robinson, W. B., and Bertino, J. J. 1976. Vineyard and cellar notes. N.Y. Agric. Exp. Stn. Special Rep. 22.

29. Pscheidt, J. W., and Pearson, R. C. 1989. Time of infection and control of Phomopsis fruit rot of grape. Plant Dis. 73:829-833.

30. Robinson, S. P., Jacobs, A. K., and Dry, I. B. 1997. A class IV chitinase is highly expressed in grape berries during ripening. Plant Physiol. 114:771-778.

31. Schnathorst, W. C. 1965. Environmental relationships in the powdery mildews. Annu. Rev. Phytopathol. 3:343-366.

32. Schneider, S., Kassemeyer, H.-H., Blaich, R., Seem, R. C., and Gadoury, D. M. 1998. Cleistothecia as primary inoculum for grape powdery mildew in Germany. (Abstr.) Phytopathology 88(suppl.):S79.

33. Stark-Urnau, M., and Kast, W. K. 1999. Development of ontogenic resistance to powdery mildew in fruit of differently susceptible grapevines (cvs. Trollinger and Lemberger). Mitteil. Klosterneuberg 49:186189.

34. Travis, J., Muza, A., Daskopoulos, D., Pearson, R. C., Gadoury, D. M., Becker, C. M., Ellis, M., and Ramsdell, D. 1994. VITIS, a grape disease management expert system. Pages 103-107 in: Proc. Int. Workshop Grapevine Downy Mildew. D. M. Gadoury and R. C. Seem, eds. N.Y. Agric. Exp. Stn. Special Rep. 68

35. Weigle, T., and Kovach, J. 1995. Grape IPM in the Northeast. Integrated Pest Management. Publ. 211, Cornell University, Ithaca, NY.

36. Wilcox, W. F., and Riegel, D. G. 1998. Evaluation of fungicide programs for control of grapevine powdery mildew, 1997. Fung. Nemat. Tests 53:107-108. 